\title{
Resource Efficiency and Productivity Changes in the G7 and BRICS Nations
}

\author{
Ming-Chung Chang ${ }^{1 *}$, Jin-Li Hu², Heng-Chu Chang ${ }^{2}$ \\ ${ }^{1}$ Department of Marketing, Kainan University, Luchu, Taoyuan City, Taiwan \\ ${ }^{2}$ Institute of Business and Management, National Chiao Tung University, Taipei City, Taiwan
}

Received: 17 September 2017

Accepted: 7 December 2017

\begin{abstract}
Energy consumption growth and greenhouse effect deterioration have caused an argument about who should lead the global climate change duty between industrialized and emerging countries. This study investigates the resource efficiency differences between nations in the Group of Seven (G7) and in an association of 5 major emerging economic bodies, including Brazil, Russia, India, China, and South Africa (BRICS). This study applies the data envelopment analysis approach to finding the BRICS group's advantages and pointing out what the G7 group should pay attention to in the future. The conclusion shows that the BRICS group has better technical efficiency improvement than the G7 group, and that the BRICS group is moving toward high energy efficiency. Findings show that the G7 suffers from technical deterioration, with some G7 members also presenting the phenomenon of high emissions.
\end{abstract}

Keywords: resource efficiency, total-factor productivity change, environmental Kuznets curve (EKC)

\section{Introduction}

Brazil, Russia, India, China, and South Africa (BRICS) are the 5 main emerging markets in the world, and their booming economies have helped drive the rapid increase in global energy consumption. Compared to Canada, France, Germany, Italy, Japan, the United Kingdom, and the United States in the Group of Seven (G7), the former are all developing countries, while the latter are developed countries. China has taken the lead among BRICS to integrate the economies of developing countries and to further increase their influence on the world economy (State Council of the People's Republic of China, 2015) [1]. Jim O'Neill, a former Goldman Sachs economist best known for coining the term BRICS,

*e-mail: changmc@mail.knu.edu.tw mentioned that these 5 rapidly developing countries have symbolized the global economic power shifting away from the G7. In the near future, the economic potential, economic growth, and population size of the BRICS may rival the G7.

Although BRICS has shown bright economic performance, economic development through overdependence on energy has caused BRICS to face environmental change, as members' carbon emissions in 2008 made up more than one-third of total global carbon emissions. A statistical investigation from the World Bank points out that the top 5 greenhouse gas (GHG) emitting countries in the world from 2006 to 2010 are the United States, Japan, China, Russia, and India. Thus, greenhouse gas reduction is not only a matter for BRICS, but also for the G7. Improving energy efficiency is one way to reduce GHG emissions; therefore, energy and emissions efficiencies among the G7 and BRICS are important issues that warrant attention. 
$\mathrm{Hu}$ and Wang (2006) [2] were the first to establish the total-factor energy efficiency (TFEE) index by means of the data envelopment analysis (DEA) approach. Some extended studies include Honma and $\mathrm{Hu}$ (2008) [3], in which the TFEE indices of 47 prefectures in Japan were measured. Many studies have extensively applied the TFEE index to different issues such as Zhou et al. (2008) [4], who measured energy efficiency by considering undesirable outputs. Zhou et al. (2010) [5] combined the method of TFEE and the Malmquist productivity index to measure carbon dioxide $\left(\mathrm{CO}_{2}\right)$ emission performance of the world's 18 top $\mathrm{CO}_{2}$ emitters in 1997-2004. Li and $\mathrm{Hu}$ (2012) [6] computed the ecological total-factor energy efficiency of 30 regions in China through the slack-based DEA model with two undesirable outputs: carbon dioxide and sulphur dioxide (SO2). The articles mentioned above show that the issue of energy and environmental (E\&E) performance should be discussed together.

Mandal (2010) [7] pointed out that when the energy efficiency measurement ignores the environmental influence of an undesirable output, then this will cause biased estimates of energy efficiency. Zhou et al. (2008) [4] reviewed hundreds of E\&E studies that separate the output factors into desirable outputs and undesirable outputs. Based on this line, Yang and Pollitt (2010) [8] suggested the necessity for properly distinguishing disposability features among undesirable outputs in a production process. Sueyoshi and Goto (2011) [9] discussed the importance of output separation in assessing the performance of energy firms, since fossil fuel power generation creates not only a good output, i.e., electricity, but also a bad output, i.e., $\mathrm{CO}_{2}$ emissions. Sueyoshi and Goto (2012a; 2012b) [10-11] used a non-radial measurement to estimate operational, environmental, and overall efficiencies.

The earliest efficiency concept was provided by Farrell (1957) [12]. Thereafter, Charnes et al. (1978) [13] and Banker et al. (1984) [14] contributed the famous radial-DEA model, which are respectively the CCR-DEA model with the assumption of constant returns to scale and the BCC-DEA model with the assumption of variable returns to scale. The criterion of efficiency means that producing more outputs correlates to less input resources. In the radial-DEA model, efficiency improvement means that the output factors or (and) input factors should have the same proportional change. When undesirable outputs are considered, the efficiency concept should change since the technology with more desirable outputs, fewer undesirable outputs, and fewer input resources should be recognized as being efficient.

The slack-based (SBM) DEA model, different from the radial-DEA model, was proposed by Tone (2001) [15], in which the input or output factors are not assumed to change proportionally. Tone (2003) [16] extended the SBM-DEA model to solve the undesirable output problem. The hybrid SBM-DEA model provided by Tone (2004) [17] also has the ability to treat the undesirable output problem. More and more papers have applied the SBM-DEA model to the analysis of environmental issues, such as Zhou and Ang (2006) [18], who proposed two slack-based efficiency measurements, in which the first slack measures environmental performance and the second measures the impact of environmental regulation.

The following paper presents recent studies on energy and environmental efficiency through the SBM-DEA model, including Zhou et al. (2013) [19], who marked the different environmental efficiencies of the power industry among Chinese provinces. Lu et al. (2013) [20] employed the hybrid SBM-DEA model to analyze $\mathrm{CO}_{2}$ emission efficiency in the Organization of Economic Cooperation and Development (OECD) countries. Chang et al. (2014) [21] examined the economic and environmental efficiency of 27 global airlines in 2010. Tao et al. (2016) [22] studied China's provincial green economic efficiency by the SBM-DEA model, which aims at the undesirable output and non-separable inputs and outputs.

The Malmquist index is a dynamic efficiency estimation indicator. Caves et al. (1982) [23] employed the Malmquist index to measure input-oriented efficiency change, which is used to measure productivity growth. Färe et al. (1994) [24] decomposed the Malmquist index and found that the sources of productivity growth are technical progress and efficiency change. Standing on the wave of global warming and climate change, the dynamic changes of energy and emissions efficiencies also have become hot topics in the literature. Ramanathan (2005) [25] used the DEA approach to investigate the energy consumption and carbon dioxide emissions of 17 countries of the Middle East and North Africa, and the patterns of changes in energy consumption and carbon dioxide emissions were also analyzed by using the Malmquist index. Kim and Kim (2012) [26] employed the DEA approach with $\mathrm{CO}_{2}$ emissions to conduct a cross-country analysis in which they identified the technical change and technological efficiency change in each economy's subsector, including agriculture, manufacturing, and service. Some studies have used the Malmquist index to measure dynamic energy efficiency, such as Wei et al. (2007) [27] and Chang (2016) [28]; some papers measured dynamic carbon emissions efficiency though the Malmquist index, such as Zhou et al. (2010) [5] and Zhang et al. (2015) [29].

In DEA articles the decision-making unit (DMU) can be a country, industry, or firms that may exhibit differences such as rich and poor countries, manufacturing and electronics industries, or public and private firms. In order to measure the performances among heterogeneous DMUs, O'Donnell et al. (2008) [30] provided the non-parametric meta-frontier approach. This approach has also been applied to the issue of energy and emissions efficiencies, such as Li and Lin (2015) [31], and Yao et al. (2015) [32]. The former paper used a meta-frontier framework to measure energy efficiency performance with $\mathrm{CO}_{2}$ emissions in 30 provinces of China, while the latter study incorporated the idea of China's region-heterogeneity to evaluate energy efficiency, carbon emission performance, and the potential of carbon emission reductions in China. Yao et al. (2015) [32] further pointed out that if DMU-heterogeneity 
is not considered in the performance evaluation, then the calculated results may cause a bias.

Our study takes the members of G7 and BRICS as an example to evaluate their resource efficiency, which includes energy and emissions efficiencies and resource productivity change. Due to heterogeneity among the 12 countries, the meta-frontier idea is applied herein in order to avoid bias in the estimated results. This paper's basic model framework is a non-oriented and non-radial DEA model, which was contributed by Chang (2015) [33] in which the best-practice frontier is used to measure operational efficiency, the worst-practice frontier is used to measure environment efficiency, and overall efficiency combines the operation and environment efficiencies. In order to apply the Chang (2015) [33] model into the meta-frontier framework and the dynamic efficiency estimation, we set up a variation of that model in which the weights of operational efficiency and environmental efficiency are one half, meaning that the 2 efficiencies are the same focus for the decision maker. Wang et al. (2015) [34] also suggested a weight setting of one half. Hence, the characteristic of this study is that we apply a variation of the Chang (2015) [33] model to static and dynamic efficiency analyses under the meta-frontier framework. This study's main contributions are as follows:

(i) The meta-frontier approach proposed by O'Donnell et al. (2008) [30] is workable under the aggregate factor framework, but it does not necessarily work under the disaggregate factor framework. However, this paper's methodology can be applied to disaggregate factor analysis under the meta-frontier framework.

(ii) The model proposed by Chang (2015) [33] was only applied to a static analysis. This paper not only provides a variation of the Chang (2015) [33] model, but also applies it to a dynamic analysis.

(iii)This study investigates resource efficiency and productivity change for the members of G7 and BRICS in order to improve their energy efficiency and carbon emissions energy according to their specific situations.

\section{Methodology}

The direction distance function (DDF) method in the DEA model not only has a strong connection between the radial and the non-radial DEA models, but a good characteristic to handle the desirable and undesirable outputs in the production process. This study applies the new DEADDF model proposed by Chang (2015) [33] to evaluate a DMU's overall efficiency, which can be decomposed into operational efficiency and environmental efficiency. For an extensive application on the measurements of dynamic efficiency and meta-frontier, this study adopts the suggestion by Wang et al. (2015) [34] of setting the weights of operational and environmental efficiencies to be one-half each, meaning that economic development and ecological protection are equally important to the policymaker. A variation of the DEA-DDF model from
Chang (2015) [33] and Wang et al. (2015) [34] measures the DMU's overall efficiency as follows:

$$
\min (1 / 2)\left(\frac{1-\frac{1}{h} \sum_{i=1}^{h} \alpha_{x i} / x_{i 0}}{1+\frac{1}{m} \sum_{j=1}^{m} \alpha_{g j} / g_{j 0}}\right)+(1 / 2)\left(\frac{1-\frac{1}{n} \sum_{k=1}^{n} \beta_{b k} / b_{k 0}}{1+\frac{1}{h} \sum_{i=1}^{h} \beta_{x i} / x_{i 0}}\right)
$$

s.t.

$$
\begin{aligned}
& X \lambda=\left(1-\frac{\alpha_{x i}}{x_{i 0}}\right) x_{i 0}, \\
& G \lambda=\left(1+\frac{\alpha_{g j}}{g_{j 0}}\right) g_{j 0}, \\
& X \lambda=\left(1-\frac{\beta_{x i}}{x_{i 0}}\right) x_{i 0}, \\
& B \lambda=\left(1-\frac{\beta_{b k}}{b_{k 0}}\right) b_{k 0}, \\
& \alpha_{x i}=\beta_{x i}, \\
& \lambda \geq 0, x_{i 0} \neq 0, g_{j 0} \neq 0, b_{k 0} \neq 0, \alpha_{x i} \geq 0, \alpha_{g j} \geq 0, \beta_{x i} \geq 0, \beta_{b k} \geq 0 .
\end{aligned}
$$

Model (1) measures DMU 0's overall efficiency. The variable $x_{i 0}$ stands for the $i^{\text {th }}$ input factor of DMU 0 , where $i=1,2, \ldots, h$; the variable $g_{j 0}$ stands for the $j^{\text {th }}$ desirable (good) output factor of DMU 0 , where $j=1,2, \ldots, m$; and the variable $b_{k 0}$ stands for the $k^{\text {th }}$ undesirable (bad) output factor of DMU 0 , where $k=1,2, \ldots, n$. The variables $a_{x i}$ and $a_{g j}$ are the slacks of the $i^{\text {th }}$ input factor and $j^{\text {th }}$ desirable output factor in the operational efficiency measurement; and the variables $b_{x i}$ and $b_{b k}$ are the respective slacks of the $i^{\text {th }}$ input factor and $k^{\text {th }}$ undesirable output factor in the environmental efficiency measurement. The constraint in model (1), i.e., $\alpha_{x i}=\beta_{x i}$, means that the input factors $x_{i}$ in the operational efficiency measurement and those in the environmental efficiency measurement exhibit the same reduction in order to estimate the productions of desirable and undesirable outputs under the same usage of input factors. The symbols $X, G$, and $B$ are the respective vectors of input, desirable output, and undesirable output. The symbol $\lambda$ is the vector of weights of the DMU 0 used for connecting the input factors and the output factors by a linear combination of each DMU. The first term in the objective function is operational efficiency, and the second term is environmental efficiency. The whole objective function is used to measure overall efficiency.

Based on Model (1), this study creates the resource efficiency measurement index (SEMI), which is a ratio of target value (TV) and real value (RV). Following this line, the SEMI for inputs, desirable outputs, and undesirable outputs are:

$$
\begin{gathered}
\operatorname{SEMI}_{i 0}=\mathrm{TV} x_{i 0} / \mathrm{RV} x_{i 0} \\
\operatorname{SEMI}_{j 0}=\mathrm{RVg}_{j 0} / \mathrm{TV} g_{j 0}, \\
\mathrm{SEMI}_{k 0}=\mathrm{TV} b_{k 0} / \mathrm{RV} b_{k 0},
\end{gathered}
$$


where the SEMI value is between 0 and 1 . If the SEMI value approaches $0(1)$, then it means that the real value is far from (close to) the target value and thus presents low (high) resource efficiency. Model (1) can also be applied to the meta-frontier issue in which there is heterogeneity among the DMUs.

Based on the meta-frontier idea from the initial work by O'Donnell et al. (2008) [30] and the application work by Wang et al. (2013) [35], all DMUs can form the meta-frontier (MF), and group DMUs can form the group frontier (GF) and then use them to calculate the technology gap ratio (TGR) as follows:

$$
\mathrm{TGR}_{0 \mathrm{z}}=\mathrm{MF}_{0 \mathrm{z}} / \mathrm{GF}_{0 \mathrm{z}}
$$

where $\mathrm{TGR}_{0 \mathrm{z}}$ represents the technology gap ratio of DMU 0 in the $z^{\text {th }}$ group, $\mathrm{MF}_{0 \mathrm{z}}$ represents DMU 0's efficiency under the meta-frontier, and $\mathrm{GF}_{0 \mathrm{z}}$ represents DMU 0's efficiency under the group frontier. Since the group frontier is a subset of the meta-frontier, $\mathrm{MF}_{0 \mathrm{z}} \leq \mathrm{GF}_{0 \mathrm{z}}$ must be hold, which causes the value of $\mathrm{TGR}_{0 z}$ to range from 0 to 1 . When the TGR value approaches $1(0)$, it means that DMU 0's production technology gap is small (large) and GF is close to (far from) MF.

Model (1) is a static efficiency measurement. This study extends Model (1) into a dynamic efficiency measurement in which the time factor is in the model:

$$
\begin{gathered}
{\left[d_{0}^{r}\left(X^{s}, G^{s}, B^{s}\right)\right]^{-1}=\min (1 / 2)\left(\frac{1-\frac{1}{h} \sum_{i=1}^{i=1} \alpha_{x i} / x_{i 0}^{s}}{1+\frac{1}{m} \sum_{j=1}^{m} \alpha_{g i} / g_{j 0}^{s}}\right)+} \\
+(1 / 2)\left(\frac{1-\frac{1}{n} \sum_{k=1}^{n} \beta_{b k} / b_{k 0}^{s}}{1+\frac{1}{h} \sum_{i=1}^{h} \beta_{x i} / x_{i 0}^{s}}\right)
\end{gathered}
$$

s.t.

$$
\begin{aligned}
X^{r} \lambda & =\left(1-\frac{\alpha_{x i}}{x_{i 0}^{s}}\right) x_{i 0}^{s} \\
G^{r} \lambda & =\left(1+\frac{\alpha_{g j}}{g_{j 0}^{s}}\right) g_{j 0}^{s} \\
X^{r} \lambda & =\left(1-\frac{\beta_{x i}^{s}}{x_{i 0}^{s}}\right) x_{i 0}^{s} \\
B^{r} \lambda & =\left(1-\frac{\beta_{b k}}{b_{k 0}^{s}}\right) b_{k 0}^{s} \\
\alpha_{x i} & =\beta_{x i} \\
\lambda \geq 0, x_{i 0}^{s} & \neq 0, g_{j 0}^{s} \neq 0, b_{k 0}^{s} \neq 0, \alpha_{x i} \geq 0, \alpha_{g j} \geq 0, \beta_{x i} \geq 0, \beta_{b k} \geq 0
\end{aligned}
$$

Given that $r=t$ and $s=t$, the variables $X^{t}, G^{t}$, and $B^{t}$ are the respective vectors of input, desirable output, and undesirable output at time $t$. The variables $x_{i 0}^{t}, g_{j 0}^{t}$, and $b_{k 0}^{t}$ are DMU 0's respective $i^{\text {th }}$ input, $j^{\text {th }}$ desirable output, and $k^{\text {th }}$ undesirable output at time $t$. Hence, $\left[d_{0}^{t}\left(X^{t}\right.\right.$, $\left.\left.G^{t}, B^{t}\right)\right]^{-1}$ is the efficiency value, which is a measurement based on the $t^{\text {th }}$ data and $t^{\text {th }}$ frontier. The efficiency value $\left[d_{0}^{t+1}\left(X^{t+1}, G^{t+1}, B^{t+1}\right)\right]^{-1}$, which is based on the $t+1^{\text {th }}$ data and $t+1^{\text {th }}$ frontier, can also be calculated by setting $r=t+1$ and $s=t+1$. Let $r=t$ and $s=t+1$ to calculate the efficiency value $\left[d_{0}^{t}\left(X^{t+1}, G^{t+1}, B^{t+1}\right)\right]^{-1}$ based on DMU 0 using the $t+1^{\text {th }}$ data and $t^{\text {th }}$ frontier. By the same way, let $r=t+1$ and $s=t$ to calculate the efficiency value $\left[d_{0}^{t+1}\left(X^{t}\right.\right.$, $\left.\left.G^{t}, B^{t}\right)\right]^{-1}$ based on DMU 0 using the $t^{\text {th }}$ data and $t+1^{\text {th }}$ frontier.

From the idea of the Malmquist productivity index (MPI), the total factor productivity (TFP) change can be measured as follows:

$$
M_{0}^{t}=d_{0}^{t}\left(X^{t+1}, G^{t+1}, B^{t+1}\right) / d_{0}^{t}\left(X^{t}, G^{t}, B^{t}\right)
$$

and

$$
M_{0}^{t+1}=d_{0}^{t+1}\left(X^{t+1}, G^{t+1}, B^{t+1}\right) / d_{0}^{t+1}\left(X^{t}, G^{t}, B^{t}\right)
$$

Equation (5a) ((5b)) implies that TFP change (TFPCH) from time $t$ to time $t+1$ is based on the reference technology at time $t(t+1)$. Via the TFPCH index, DMU 0's MPI can be defined as:

$$
\begin{gathered}
M_{0}=\left(M_{0}{ }^{t} \times M_{0}{ }^{t+1}\right)^{1 / 2} \\
=\left(\frac{d_{0}^{t+1}\left(X^{t+1}, G^{t+1}, B^{t+1}\right)}{d_{0}^{t}\left(X^{t}, G^{t}, B^{t}\right)}\right)\left(\frac{d_{0}^{t}\left(X^{t+1}, G^{t+1}, B^{t+1}\right)}{d_{0}^{t+1}\left(X^{t+1}, G^{t+1}, B^{t+1}\right)} \times\right. \\
\left.\frac{d_{0}^{t}\left(X^{t}, G^{t}, B^{t}\right)}{d_{0}^{t+1}\left(X^{t}, G^{t}, B^{t}\right)}\right)^{1 / 2}
\end{gathered}
$$

where the first term is the technical efficiency change (TECH) index, and the second term is the technical change $(\mathrm{TCH})$ index.

\section{Empirical Analysis}

This section takes the members of BRICS and G7 as an example to discuss resource efficiency and productivity change.

\section{Data Description}

The data source of BRICS and G7 is the website of the World Bank. The empirical analysis uses three input factors, including capital, labor, and energy use, one desirable output (i.e., gross domestic product - GDP), and one undesirable output (i.e., $\mathrm{CO}_{2}$ emissions). The data period is from 2000 to 2010, and all financial data are transferred into real variables with the basic price level at the year 2010. The variable choice in this paper is the same as the E\&E research by Mandal (2010) [7], Guo et al. (2011) [36], Choi et al. (2012) [37], and Wu et al. (2012) [38]. The data descriptive statistics are in Table 1.

The information in Table 1 presents the members of G7 and BRICS in which the rich countries always have higher real GDP, lower $\mathrm{CO}_{2}$ emissions, higher real capital, lower labor numbers, and lower of energy use numbers than poor countries. However, some interesting points appear in the standard deviation of variables in which 
Table 1. Descriptive statistics for all input and output factors.

\begin{tabular}{|c|c|c|c|c|c|c|}
\hline \multicolumn{2}{|c|}{} & \multicolumn{2}{c|}{ Output } & \multicolumn{3}{c|}{ Input } \\
\hline \multicolumn{2}{|c|}{} & $\begin{array}{c}\text { Real GDP } \\
\text { (Million US\$) }\end{array}$ & $\begin{array}{c}\mathrm{CO}_{2} \\
(\mathrm{Kt})\end{array}$ & $\begin{array}{c}\text { Real capital } \\
\text { (Million US\$) }\end{array}$ & $\begin{array}{c}\text { Labor } \\
\text { (Persons) }\end{array}$ & $\begin{array}{c}\text { Energy use } \\
\text { (Kt of oil equivalent) }\end{array}$ \\
\hline Mean & G7 & 4206540 & 1366690 & 4370559 & 58859025 & 574834 \\
\hline & BRICS & 1446467 & 1914985 & 1881154 & 354077382 & 664242 \\
\hline St. dev. & G7 & 4260624 & 1783990 & 5777614 & 52709973 & 702937 \\
\hline & BRICS & 1180178 & 2110761 & 2540988 & 360492782 & 622428 \\
\hline Min & G7 & 872716 & 356924 & 11566 & 18707977 & 164858 \\
\hline & BRICS & 172139 & 321622 & 37803 & 18303999 & 109264 \\
\hline Max & G7 & 15228476 & 5828697 & 26351418 & 186462122 & 2337014 \\
\hline
\end{tabular}

rich countries have a large deviation on the real GDP, real capital, and energy use; and poor countries show a large deviation on $\mathrm{CO}_{2}$ emissions and the amount of labor. For economic performance, there is a large gap among the G7 members while a relatively consistent economic outcome appears among BRICS; for environmental performance, a large $\mathrm{CO}_{2}$ emissions gap occurs in BRICS, and a large energy use gap occurs among the G7.

Generally speaking, a G7 country with a capitalintensive industry owns more wealth than a member of BRICS with a labor-intensive industry. Since Brazil, Russia, India, and China make up $43 \%$ of the world's population (Yao et al., 2009) [39], these countries always use more labor at a relatively cheaper price than capital as the input factor. According to information from the World Bank (2014) [40], the energy consumption of BRICS is more than that of the G7 in 2010; however, this phenomenon is continuous, since
Table 1 shows that the mean of energy consumption of BRICS from 2000 to 2010 is larger than that of the G7. Table 1 also shows that the mean of energy intensity of BRICS (0.459) is higher than that of the G7 (0.137); and the mean of carbon intensity of BRICS (1.324) is far higher than that of the G7 (0.325), implying that the world will face energy and ecological catastrophes if these emerging countries' consumption of energy continues to be inefficient.

The result of G7's absolute advantage changes when the target values of GDP, $\mathrm{CO}_{2}$ emissions, and energy consumption are considered by the DEA approach such as by Chang (2015) [33], who found that the G7 group has weaker performance in the room for improvement of carbonization value than the BRICS group before 2005. Hence, the DEA approach is valuable for analyzing and comparing the different resource efficiencies and productivity changes between the G7 and BRICS.

Table 2. Overall efficiency for G7 and BRICS.

\begin{tabular}{|c|c|c|c|c|c|c|c|c|c|c|c|c|c|}
\hline & Canada & France & Germany & Italy & Japan & $\begin{array}{c}\text { United } \\
\text { Kingdom }\end{array}$ & $\begin{array}{c}\text { United } \\
\text { States }\end{array}$ & Brazil & China & India & $\begin{array}{c}\text { Russian } \\
\text { Federation }\end{array}$ & $\begin{array}{c}\text { South } \\
\text { Africa }\end{array}$ & Average \\
\hline 2000 & 0.642 & 1.000 & 0.814 & 0.881 & 1.000 & 0.937 & 1.000 & 0.945 & 0.327 & 0.429 & 0.371 & 0.405 & 0.729 \\
\hline 2001 & 0.660 & 1.000 & 0.820 & 1.000 & 1.000 & 1.000 & 1.000 & 0.854 & 0.389 & 0.460 & 0.372 & 1.000 & 0.796 \\
\hline 2002 & 0.637 & 1.000 & 0.823 & 0.962 & 0.918 & 1.000 & 1.000 & 0.757 & 0.379 & 0.439 & 0.351 & 0.358 & 0.719 \\
\hline 2003 & 0.606 & 1.000 & 0.830 & 1.000 & 0.871 & 1.000 & 1.000 & 0.689 & 0.333 & 0.418 & 0.393 & 1.000 & 0.762 \\
\hline 2004 & 0.608 & 1.000 & 0.825 & 1.000 & 0.830 & 1.000 & 1.000 & 0.679 & 0.318 & 0.405 & 0.352 & 1.000 & 0.751 \\
\hline 2005 & 0.638 & 1.000 & 0.826 & 0.949 & 0.819 & 1.000 & 1.000 & 0.791 & 0.332 & 0.414 & 0.450 & 1.000 & 0.768 \\
\hline 2006 & 0.660 & 1.000 & 0.817 & 0.893 & 0.767 & 1.000 & 1.000 & 1.000 & 0.344 & 0.404 & 0.478 & 1.000 & 0.780 \\
\hline 2007 & 0.635 & 1.000 & 0.824 & 0.882 & 0.704 & 1.000 & 1.000 & 1.000 & 0.352 & 0.448 & 0.422 & 0.441 & 0.726 \\
\hline 2008 & 0.629 & 1.000 & 1.000 & 1.000 & 0.730 & 1.000 & 1.000 & 1.000 & 0.382 & 0.352 & 0.482 & 0.309 & 0.740 \\
\hline 2009 & 0.617 & 1.000 & 1.000 & 1.000 & 0.810 & 0.885 & 1.000 & 1.000 & 1.000 & 0.351 & 0.339 & 0.309 & 0.776 \\
\hline 2010 & 1.000 & 1.000 & 1.000 & 1.000 & 0.940 & 1.000 & 1.000 & 1.000 & 1.000 & 0.408 & 0.424 & 0.445 & 0.851 \\
\hline Average & 0.667 & 1.000 & 0.871 & 0.961 & 0.853 & 0.984 & 1.000 & 0.883 & 0.469 & 0.412 & 0.403 & 0.661 & \\
\hline
\end{tabular}




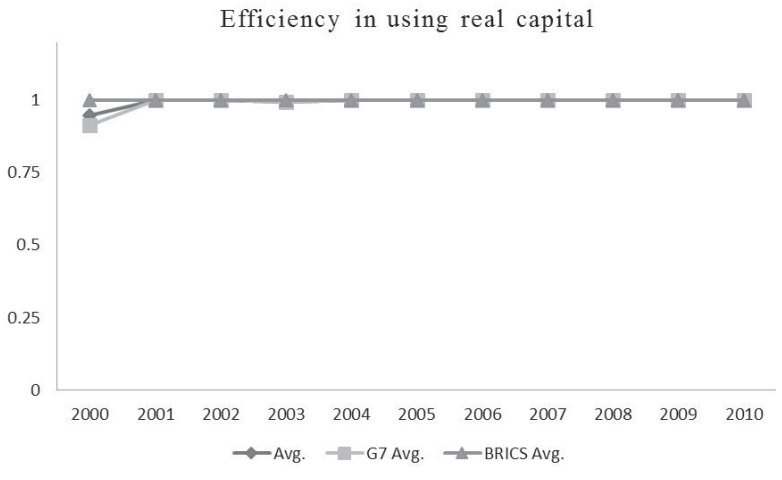

Efficiency in using labor

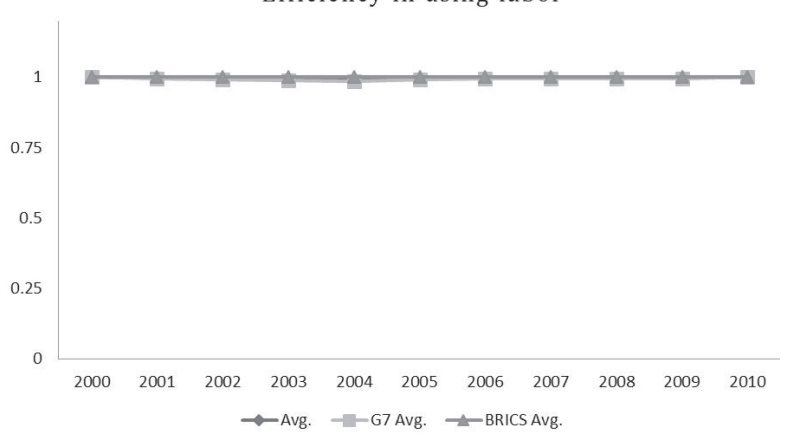

Efficiency in using energy

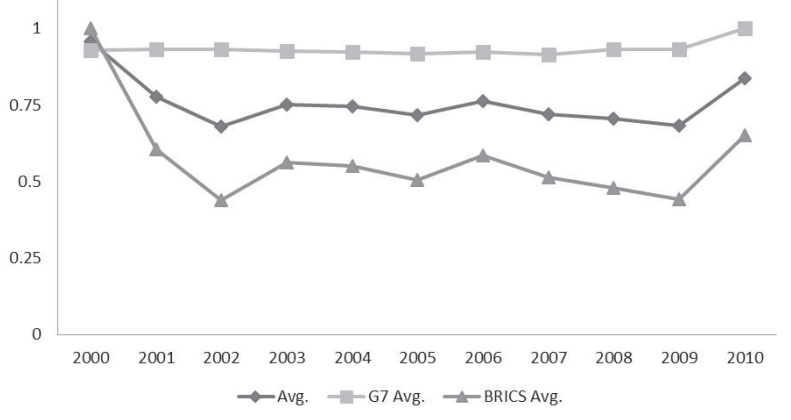

Efficiency in performance of GDP

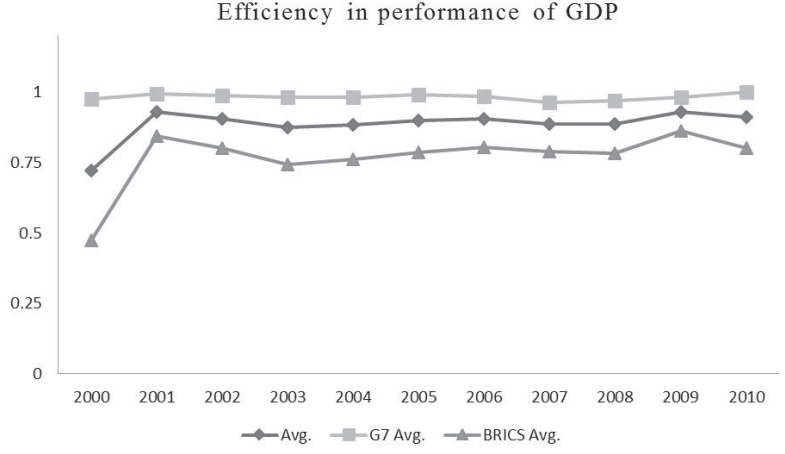

Efficiency in performance of $\mathrm{CO} 2$ emissions

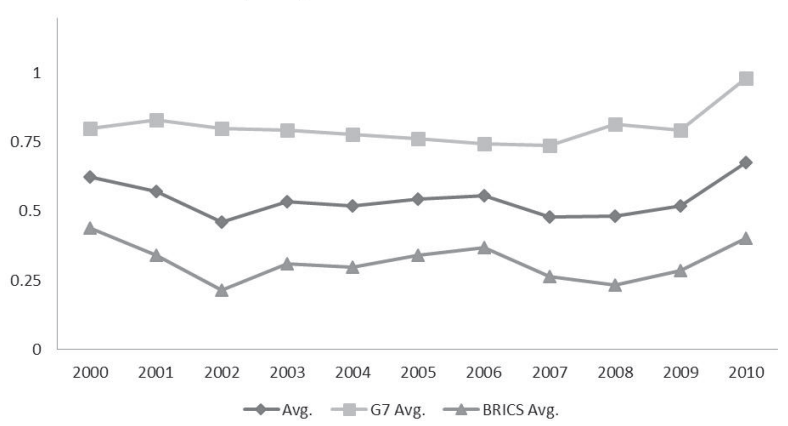

Fig. 1. Resource use efficiency for all input and output factors.

\section{Overall Efficiency and Disaggregate Efficiency}

Table 2 shows the values of overall efficiency for the 12 countries of the G7 and BRICS, which are estimated by Model (1). Within the 12 countries, only France and the United States among the G7 reach the best-practice frontier, while no BRICS member reaches it. The result fits common knowledge that a developed country has better economic and environmental efficiency than a developing country. The average overall efficiency for all countries reaches the highest in 2010, in which 8 of the 12 countries go to the best frontier, except for Japan, India, Russia, and South Africa. The worst 3 average overall efficiencies from 2000 to 2010 are Russia, India, and China.

The overall efficiency of the G7 is generally better than that of BRICS (Table 2). Hence, the study divides the 12 countries into the G7 and BRICS groups in order to discuss the 2 groups' disaggregate efficiencies. By this way, the source of overall inefficiency can be investigated. Based on Eq. (2), the resource use efficiency for all input and output factors can be computed, and they are represented by the figures as follows.

Fig. 1 shows that the efficiencies of real capital and labor for the G7 and BRICS groups are similar, except for real capital efficiency in 2000. These 2 groups have a large difference in energy use efficiency. After 2000, the energy use efficiency of the G7 group is always larger than that of the BRICS group. Specifically, the G7 group's energy use efficiency always maintains a constant trend, but there is a large wave in the BRICS group's energy efficiency performance. On the product side, no matter for GDP or $\mathrm{CO}_{2}$ emissions, the performances of the G7 are always better than that of BRICS; and their GDP performances are better than their $\mathrm{CO}_{2}$ emission ones. Hence, the G7 and BRICS have similar performances on traditional input factors such as capital and labor, but have a large performance difference on energy use and $\mathrm{CO}_{2}$ emissions. The large difference in GDP performance and $\mathrm{CO}_{2}$ emissions is caused by energy use rather than traditional input factors.

\section{Productivity Change Analysis}

The paper uses Eq. (3) to measure the TGR of overall efficiency in the G7 and BRICS groups. Based on the TGR definition, if the TGR value is closer to one, then it implies that the individual frontier is also closer to the overall frontier, i.e., the meta-frontier. Fig. 2 shows the trend of the average TGR of the G7 and BRICS groups from 2000 to 2010 , respectively; there is a large gap in the TGR value between the G7 and the BRICS groups in which the TGR values in the former are stable above 0.998 , and the TGR values in the latter have a large fluctuation during the data period. It implies that the G7 group, with the top technology in resource management, possesses the best utilization yield in resource and performance; on the contrary, the BRICS group has weaker resource management technology than G7. This result is consistent with the fact that the G7 group exhibits high efficiencies 


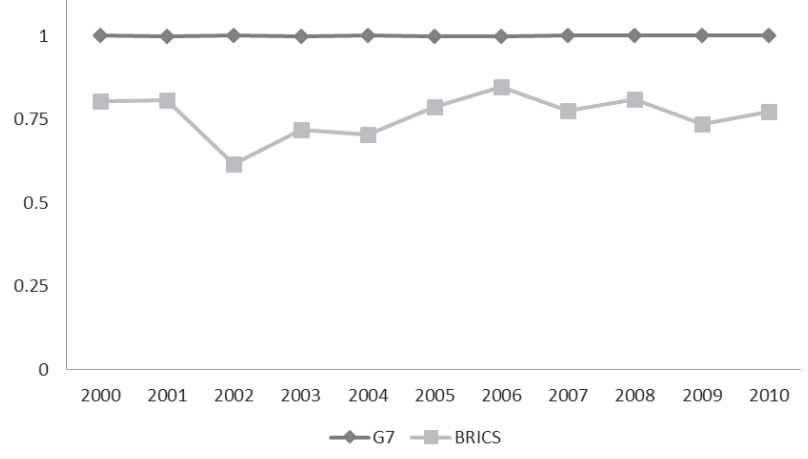

Fig. 2. Technology gap ratio in the G7 and BRICS groups.

in energy use, GDP, and $\mathrm{CO}_{2}$ emissions. Hence, the BRICS group should further update and import advanced technology from the G7 group to improve its own energy management and to be more aware of environmental protection. De Castro Camioto et al. (2016) [41] assert that the G7 and BRICS are statistically different groups.

This paper uses Eqs (4), (5), and (6) to estimate TFPCH, TECH, and TCH. Table 3 demonstrates TFPCH for each member of the G7 and BRICS during the data period. When the TFP value equals one, it indicates that the country's productivity is the same as the productivity in the previous year; when the TFP value is larger (smaller) than one, it indicates that the country's productivity has improved (deteriorated) relative to productivity in the previous year. The result in Table 3 shows that the average values of TFP during the whole data period in the 2 groups are $99.5 \%$ and $89.9 \%$, respectively. Both of their average values of TFP are smaller than one, which implies that the 2 groups show deterioration in total factor productivity from 2000 to 2010 . The gaps between $99.5 \%$, $89.9 \%$, and $100 \%$ are $0.5 \%$ and $10.1 \%$, meaning that the G7 and BRICS groups face TFP deterioration at average rates of $0.5 \%$ and $10.1 \%$ per year. The observation for each year's information notes that the BRICS group's TFP continuously deteriorates from 2000 to 2008. More specifically, China's TFP had an obvious improvement in 2008-2009 in which the TFP growth rate is $150.8 \%$. This phenomenon may relate to China being the host of the 2008 Olympic Games. In that year, the Chinese government struggled to keep everything at a good level for a successful presentation of the Olympic Games. In addition, each country of BRICS had TFP improvement in 2009-2010, in which South Africa had the largest TFP improvement among the 5 at $19.6 \%$.

The information in the final column of Table 3 shows that 3 countries out of the whole sample of Italy, Japan, and China have a positive TFP change during the data period, and their TFP changes for each year are 3.7\%, $2.8 \%$, and $5.1 \%$, respectively. The countries with a TFP value of one are France and the United States, while negative TFP growth appeared in 7 countries, with the top 2 being South Africa with a TFP change of $-26.6 \%$ and Russia at $-17.4 \%$ per year. The trend of TFPCH for each country from 2000 to 2010 shows that South Africa had the largest TFP deterioration in 2001-2002, and its deterioration ratio is $64.5 \%$, followed by Russia, Canada,

Table 3. Total factor productivity change for each member of the G7 and BRICS.

\begin{tabular}{|c|c|c|c|c|c|c|c|c|c|c|c|c|}
\hline Group & Nation & $\begin{array}{c}2000 \\
-2001\end{array}$ & $\begin{array}{c}2001 \\
-2002\end{array}$ & $\begin{array}{c}2002 \\
-2003\end{array}$ & $\begin{array}{c}2003 \\
-2004\end{array}$ & $\begin{array}{c}2004 \\
-2005\end{array}$ & $\begin{array}{c}2005 \\
-2006\end{array}$ & $\begin{array}{c}2006 \\
-2007\end{array}$ & $\begin{array}{c}2007 \\
-2008\end{array}$ & $\begin{array}{c}2008 \\
-2009\end{array}$ & $\begin{array}{c}2009 \\
-2010\end{array}$ & Avg. \\
\hline G7 & Canada & 0.800 & 0.792 & 0.998 & 1.043 & 1.023 & 1.037 & 1.010 & 0.972 & 0.766 & 1.300 & 0.963 \\
\hline & France & 1.000 & 1.000 & 1.000 & 1.000 & 1.000 & 1.000 & 1.000 & 1.000 & 1.000 & 1.000 & 1.000 \\
\hline & Germany & 0.892 & 0.932 & 1.004 & 0.997 & 0.915 & 0.911 & 1.129 & 1.011 & 0.889 & 0.887 & 0.954 \\
\hline & Italy & 1.001 & 0.981 & 1.093 & 1.080 & 1.021 & 1.039 & 1.100 & 1.065 & 1.000 & 1.000 & 1.037 \\
\hline & Japan & 1.000 & 0.987 & 1.073 & 1.041 & 0.998 & 0.971 & 0.995 & 1.081 & 1.084 & 1.061 & 1.028 \\
\hline & $\begin{array}{c}\text { United } \\
\text { Kingdom }\end{array}$ & 0.991 & 1.000 & 1.000 & 1.000 & 1.000 & 1.000 & 1.000 & 1.000 & 0.872 & 0.986 & 0.984 \\
\hline & $\begin{array}{c}\text { United } \\
\text { States }\end{array}$ & 1.000 & 1.000 & 1.000 & 1.000 & 1.000 & 1.000 & 1.000 & 1.000 & 1.000 & 1.000 & 1.000 \\
\hline G7 Avg. & 0.952 & 0.953 & 1.023 & 1.023 & 0.993 & 0.993 & 1.032 & 1.018 & 0.939 & 1.027 & 0.995 \\
\hline BRICS & Brazil & 0.863 & 0.834 & 0.983 & 1.031 & 1.110 & 1.036 & 1.000 & 1.000 & 1.000 & 1.000 & 0.983 \\
\hline & China & 0.931 & 0.871 & 0.867 & 0.915 & 0.962 & 0.987 & 1.034 & 1.035 & 2.508 & 1.000 & 1.051 \\
\hline & India & 0.665 & 0.912 & 0.977 & 0.991 & 1.001 & 0.986 & 1.094 & 0.853 & 0.973 & 1.032 & 0.941 \\
\hline & $\begin{array}{c}\text { Russian } \\
\text { Federation }\end{array}$ & 0.598 & 0.580 & 1.081 & 1.063 & 1.089 & 0.916 & 0.953 & 0.737 & 0.504 & 1.039 & 0.826 \\
\hline & $\begin{array}{c}\text { South } \\
\text { Africa }\end{array}$ & 0.953 & 0.355 & 1.070 & 1.000 & 0.646 & 0.632 & 0.411 & 0.691 & 0.900 & 1.196 & 0.734 \\
\hline BRICS Avg. & 0.788 & 0.671 & 0.993 & 0.999 & 0.945 & 0.900 & 0.850 & 0.852 & 1.021 & 1.051 & 0.899 \\
\hline
\end{tabular}


and Brazil, whose TFP deterioration ratios are $42 \%$, $20.8 \%$, and $16.6 \%$, respectively.

After 2005, when the Kyoto Protocol became enforced, many countries in the world began to pay attention to a balance between economic growth and environmentally sustainable development. The information in Table 3 shows that Canada had the largest TFP improvement of $30 \%$ in 2009-2010, whereas 3 members of BRICS also presented positive TFP change. The highest TFP growth is South Africa with a growth ratio of $19.6 \%$, followed by Russia and India at $3.9 \%$ and $3.2 \%$, respectively. The reason these 3 had TFP growth is because their real GDP increased and $\mathrm{CO}_{2}$ emissions decreased.

Table 3 also presents the average annual TFPCH for the 2 groups. Before 2008, TFPCH of the G7 is always better than that of BRICS. After 2008, TFPCH of the G7 fell rapidly and then recovered quickly during the next year. Canada had TFP deterioration of $23.4 \%$, followed by the United Kingdom at $12.8 \%$ and Germany at $11.1 \%$ for 2008-2009. Based on this result, the global financial crisis from 2008 to 2009 had a more serious impact on the G7 than on BRICS.

Table 4 presents the values of TECH, TCH, and TFPCH in which TFPCH is the product of TECH and TCH. The DMU clusters to the frontier or disperses from the frontier, depending on its TECH value being greater or less than one, and the catch-up or fall-behind effect of a DMU depends on its TCH value being greater or less than one. According to the information in Table 4, the TFP for all countries of the G7 and BRICS declined $4.6 \%$ per year from 2000-2010. The reason that TFP deteriorates is caused by the technology recession, since the TCH value is 0.937 less than one. This result illustrates that the technology regression in all sample countries has an average value of $6.3 \%$ per year; on the contrary, all sample countries have technical efficiency progression at an average value of $1.8 \%$ per year.

For a comparison between the G7 and BRICS, the latter has a more serious technology regression than the former, but the latter has better technical efficiency improvement than the former. Even so, all countries of BRICS face technological deterioration during the data period. In terms of technical efficiency, only 2 countries (i.e., Japan and India) face technical efficiency deterioration, which is caused by inefficient resource use. From the viewpoint of TFPCH, the G7 group and the BRICS group face TFP deterioration of $0.5 \%$ and $10.1 \%$ per year, respectively, indicating that the latter has a more serious recession in TFP than the former. The source of TFP deterioration is caused by technology recession instead of technical efficiency change.

\section{Discussion}

This section extends the discussion to disaggregate efficiency by using the Boston Consulting Group (BCG) matrix and the environmental Kuznets curve (EKC).

\section{Disaggregate Efficiency in the BCG Matrix}

Our study uses the BCG matrix with the $\mathrm{x}$-axis as energy efficiency and $y$-axis as emissions efficiency to discuss the development trace of the G7 and BRICS. Based on the idea of the BCG matrix, the average values of energy efficiency and emissions efficiency divide the

Table 4. TECH, TCH, and TFPCH for each country from 2000 to 2010.

\begin{tabular}{|c|c|c|c|c|}
\hline Group & States & $\begin{array}{c}\text { Technical efficiency change } \\
\text { (TECH) }\end{array}$ & $\begin{array}{l}\text { Technical change } \\
\text { (TCH) }\end{array}$ & $\begin{array}{l}\text { Total factor productivity change } \\
\text { (TFPCH) }\end{array}$ \\
\hline \multirow{7}{*}{$\mathrm{G} 7$} & Canada & 1.045 & 0.921 & 0.963 \\
\hline & France & 1.000 & 1.000 & 1.000 \\
\hline & Germany & 1.021 & 0.935 & 0.954 \\
\hline & Italy & 1.013 & 1.024 & 1.037 \\
\hline & Japan & 0.994 & 1.035 & 1.028 \\
\hline & United Kingdom & 1.006 & 0.978 & 0.984 \\
\hline & United States & 1.000 & 1.000 & 1.000 \\
\hline \multicolumn{2}{|r|}{ G7 Avg. } & 1.011 & 0.984 & 0.995 \\
\hline \multirow{5}{*}{ BRICS } & Brazil & 1.006 & 0.977 & 0.983 \\
\hline & China & 1.118 & 0.940 & 1.051 \\
\hline & India & 0.995 & 0.945 & 0.941 \\
\hline & Russian Federation & 1.014 & 0.815 & 0.826 \\
\hline & South Africa & 1.009 & 0.727 & 0.734 \\
\hline \multicolumn{2}{|r|}{ BRICS Avg. } & 1.027 & 0.875 & 0.899 \\
\hline \multicolumn{2}{|r|}{ Avg. } & 1.018 & 0.937 & 0.954 \\
\hline
\end{tabular}




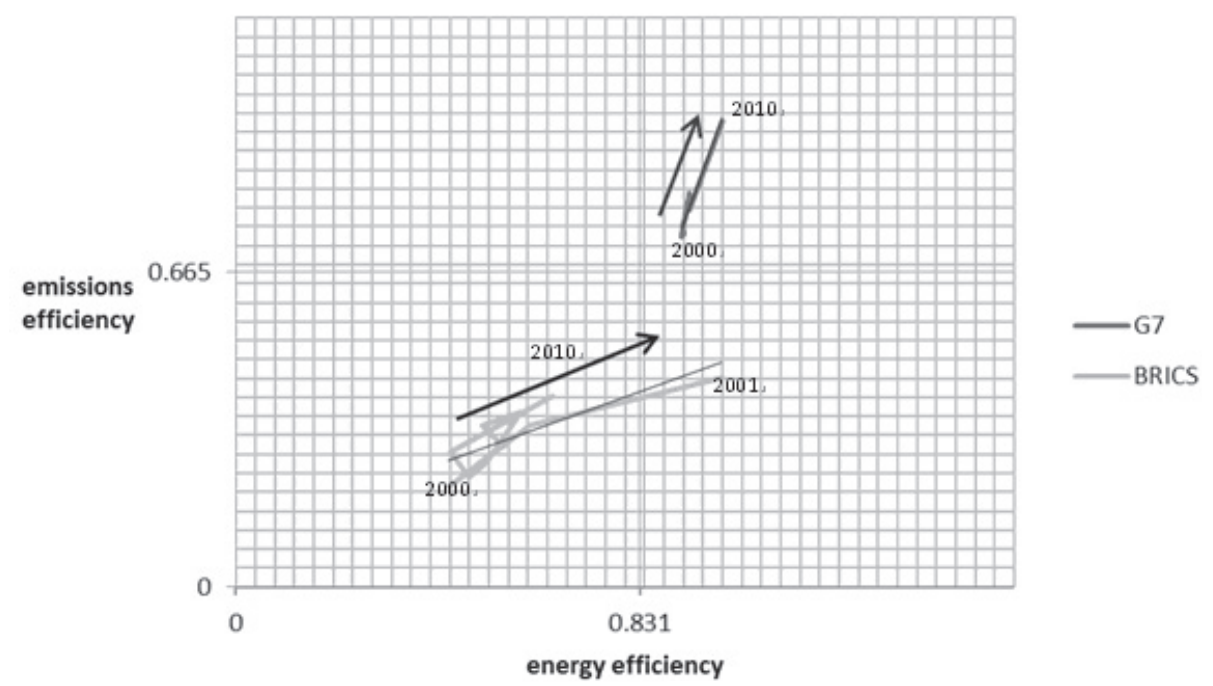

Fig. 3. The development trace of the G7 and BRICS.

plane into 4 quadrants. The first quadrant stands for "green area" and includes the DMU with high energy efficiency and emissions efficiency values; the second quadrant stands for "question mark area" and includes the DMU with low energy efficiency but high emissions efficiency; the third quadrant stands for "traditional area" and includes the DMU with low energy efficiency and emissions efficiency; and the fourth quadrant stands for "developing area" and includes the DMU with high energy efficiency, but low emissions efficiency. The development trace shows that the G7 group is always located in the "green area" and the BRICS group is initially located in the "traditional area" and then moved to the "developing area." The trace of the G7 group means that it owns mature energy and environmental management, and the trace of the BRICS group means that it has improved in energy and environmental management over time.
In order to find the reasons that cause the differing energy and emissions efficiencies between the G7 and BRICS, the study adopts the 2-sample t-test to find the answer. The explanation variables found on the World Bank website and the test results are listed in Table 5, in which the pump price for diesel fuel, pump price for gasoline, and energy intensity significantly impact the efficiency values of the 2 groups. The low pump prices of diesel fuel and gasoline mean that a country incurs a low cost to use the resources of diesel fuel and gasoline, which will result in a resource waste problem. The result also illustrate that BRICS have lower energy efficiency than the G7 (Fig. 3). Energy intensity also significantly impacts energy efficiency and emissions efficiency in the G7 and BRICS, since a lot of energy use with low cost creates less GDP, but a lot of $\mathrm{CO}_{2}$ emissions in the BRICS group. The main reason for the big differences in

Table 5. The results of the 2-sample T-test.

\begin{tabular}{|c|c|c|}
\hline Variable & Definition $^{1}$ & P-value ${ }^{2}$ \\
\hline Oil rents & $\begin{array}{l}\text { Oil rents are the difference between the value of crude oil production at world } \\
\text { prices and total costs of production. }\end{array}$ & 0.282 \\
\hline Pump price for diesel fuel & $\begin{array}{l}\text { Fuel prices refer to the pump prices of the most widely sold grade of diesel } \\
\text { fuel. Prices have been converted from the local currency to U.S. dollars. }\end{array}$ & $0.019^{* *}$ \\
\hline Pump price for gasoline & $\begin{array}{l}\text { Fuel prices refer to the pump prices of the most widely sold grade of gasoline. } \\
\text { Prices have been converted from the local currency to U.S. dollars. }\end{array}$ & $0.045^{* *}$ \\
\hline $\mathrm{CO}_{2}$ emissions from transport & $\begin{array}{l}\mathrm{CO}_{2} \text { emissions from transport contain emissions from the combustion of fuel } \\
\text { for all transport activity. }\end{array}$ & 0.237 \\
\hline $\begin{array}{l}\mathrm{CO}_{2} \text { emissions from manufacturing } \\
\text { and construction industries }\end{array}$ & $\begin{array}{l}\mathrm{CO}_{2} \text { emissions from manufacturing industries and construction contains } \\
\text { the emissions from combustion of fuels in industry. }\end{array}$ & 0.154 \\
\hline $\begin{array}{l}\mathrm{CO}_{2} \text { emissions from electricity and } \\
\text { heat production }\end{array}$ & $\begin{array}{l}\mathrm{CO}_{2} \text { emissions from electricity and heat production is the sum of three IEA } \\
\text { categories of } \mathrm{CO}_{2} \text { emissions. }\end{array}$ & 0.285 \\
\hline Energy intensity & $\begin{array}{l}\text { Energy intensity is the ratio between energy supply and GDP measured } \\
\text { at purchasing power parity. Energy intensity is an indication of how much } \\
\text { energy is used to produce one unit of economic output. }\end{array}$ & $0.068^{*}$ \\
\hline
\end{tabular}

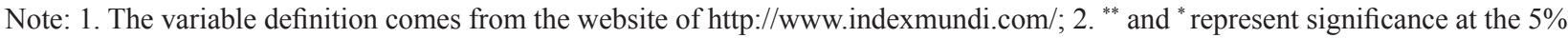
and $10 \%$ levels, respectively 
GDP, $\mathrm{CO}_{2}$ emissions, and energy use between the G7 and BRICS is due to the difference in TFP, and the difference in TFP is caused by the technology gap.

\section{The Environmental Kuznets Curve}

In the past, economic development and environmental quality have not always kept a strong balance. The environmental Kuznets curve (EKC) can describe the relationship between economic development and environmental protection. Based on the EKC idea, income per capita is used as a proxy for economic development, and pollution emissions are used as a proxy for environmental quality. The theoretical EKC was constructed as an inverted U-shaped relationship in which environmental pressure increases up to a certain level as income rises; after that, environmental pressure decreases (Dinda, 2004) [42]. Stern et al. (1996) [43] empirically supported that there is an inverted U-shaped relationship between environmental degradation and income per capita.

This paper employs per capita GDP as a proxy for economic growth and per capita $\mathrm{CO}_{2}$ emissions as a proxy for environmental pressure. The empirical result appears in Fig. 4, in which there is an N-shaped EKC for all the G7 and BRICS. Fig. 4 also depicts the relationship between per capita GDP and per capita energy use, which is also $\mathrm{N}$-shaped. Some empirical studies support the finding that EKC is N-shaped instead of inverted U-shaped, such as Grossman and Krueger (1991) [44], who were the pioneers in finding the $\mathrm{N}$-shaped EKC, followed by Akbostanc1 et al. (2009) [45], He and Richard (2010) [46], and Fodha and Zaghdoud (2010) [47]. Aside from the N-shaped EKC, 2 curves in Fig. 4 have a similar trace, which implies that the $\mathrm{CO}_{2}$ emissions and the amount of energy use have a direct relationship, and that the $\mathrm{CO}_{2}$ emissions and energy use are also related.
This paper's EKC does not exhibit an inverted U-shape. The countries on the left side of EKC are almost all developing countries with low per capita GDP, while the others on the right side of EKC are developed ones with high per capita GDP. Two critical points are on the N-shaped EKC in which environmental quality improves when the country's per capita GDP increases, and then environmental quality deteriorates when the country's per capita GDP further increases. Under the inverted U-shaped EKC framework, the study divides the countries into rich and poor countries; however, under the N-shaped EKC framework, the countries need to be divided into three levels: low, medium, and high incomes. Levinson (2002) [48] provided 2 viewpoints to argue for the inverted U-shaped EKC. The first point is that the data scale may impact the EKC path to specifically analyze long-term data; and the second is that the EKC shape may be influenced by the side effect of desirable output.

Fig. 4 shows that the countries with low per capita GDP include Brazil, China, and India, which also have relatively high per capita $\mathrm{CO}_{2}$ emissions, and high per capita GDP countries also have relatively more per capita $\mathrm{CO}_{2}$ emissions. Countries with per capita GDP at the medium level own a relatively high per capita GDP versus the low per capita GDP countries, but their per capita $\mathrm{CO}_{2}$ emissions are lower than the low per capita GDP countries and the high per capita GDP ones. Hence, the N-shaped EKC is the result that pools all members of the G7 and BRICS together, and their per capita GDP can be divided into 3 different levels. Furthermore, countries with low per capita GDP and high per capita GDP face a high level of $\mathrm{CO}_{2}$ emissions; only those countries with per capita GDP at the medium level face the lowest $\mathrm{CO}_{2}$ emissions. The N-shaped EKC also implies that developed countries should take note of environmental awareness again.

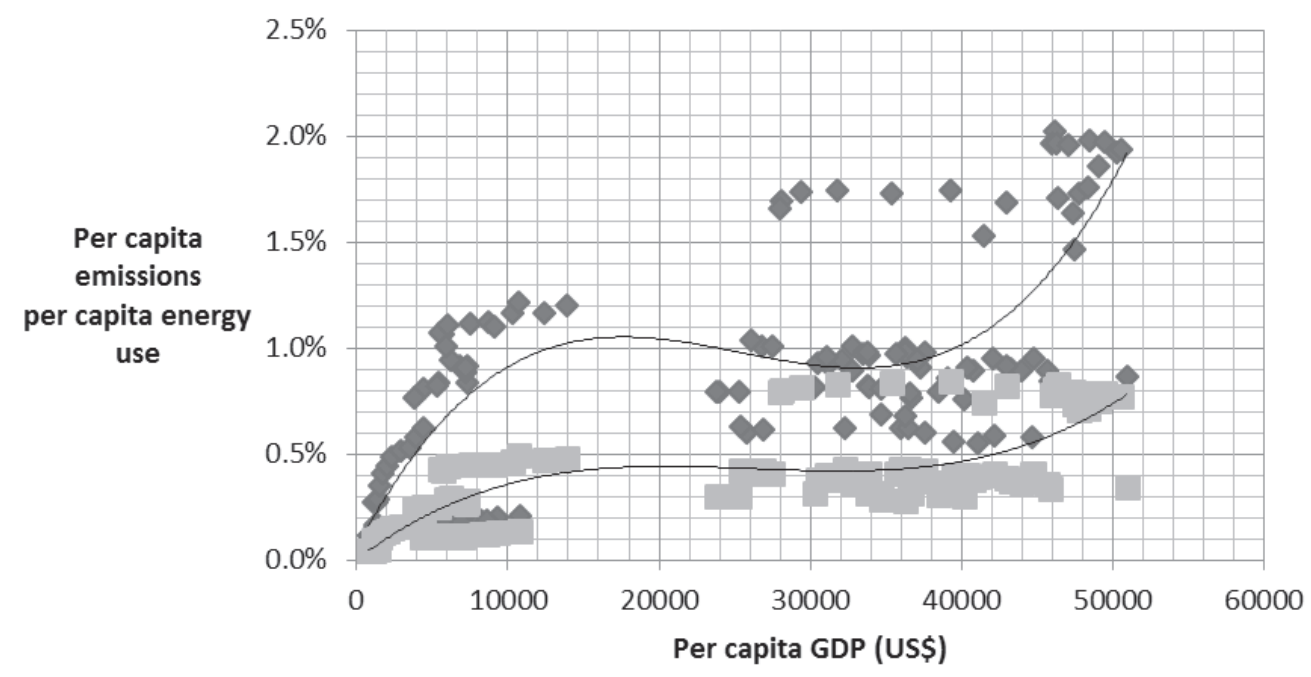

$\checkmark$ EKC for per capita emissions $\quad$ EKC for per capita energy use

Fig. 4. Environmental Kuznets curve. 


\section{Conclusions}

This study investigates resource efficiency and productivity change among the G7 and BRICS by applying the non-oriented static and dynamic DEA models. Some extension issues such as the technical gap and EKC are also discussed by the meta-frontier approach and BCG matrix. The study results show that TFP for all of the G7 and BRICS deteriorates at an average value of $4.6 \%$ due to technical recession. Specifically, some G7 countries suffered from a serious technical recession during the 2008 global financial crisis. Even so, all 12 sample countries still exhibit positive technical efficiency progression during the data period. A comparison between the G7 and BRICS groups shows that the former has better TFP and technical levels than the latter, whereas the latter has larger technical efficiency improvement than the former. This result shows that the BRICS group is moving to the frontier and also implies that resource use in this group is becoming more and more effective. Being the main emerging market in the world, China exhibits TFP improvement, but this improvement is caused by technical efficiency improvement instead of technical progression.

The BCG matrix analysis shows that the G7 group is always located in the green area, which stands for high energy efficiency and high $\mathrm{CO}_{2}$ emissions efficiency. However, the BRICS group is moving from the traditional area, which stands for low energy efficiency and low $\mathrm{CO}_{2}$ emissions efficiency, to the developing area, which stands for low $\mathrm{CO}_{2}$ emissions efficiency, but high energy efficiency. This result implies that the energy efficiency of the BRICS group is improving. This paper finds that the reason includes the cheap prices on diesel fuel and gasoline, and the high energy intensity in the BRICS group that causes the BRICS group to be more ineffective than the G7 group. This paper also finds an N-shaped EKC when polling all 12 countries. This result is different from the theoretical inverted U-shaped EKC. The N-shaped EKC implies that high per capita $\mathrm{CO}_{2}$ emissions appear not only in low per capita GDP countries, but also in high per capita ones, and that countries with a medium per capita GDP level have the lowest per capita $\mathrm{CO}_{2}$ emissions.

According to the general idea, the G7's TFP is superior to that of the BRICS group. However, our paper finds that the BRICS group's advantages include its technological efficiency improvement being better than the G7 group, and its energy efficiency is also improving over time. In addition, we also note that the G7 group should pay attention in the future as it suffers from technical deterioration, and the phenomenon of high $\mathrm{CO}_{2}$ emissions also appears in some G7 members. A future study can continuously extend the data period by adding the latest data to encompass resource use efficiency, productivity change, and EKC shape.

\section{Acknowledgements}

The helpful comments of an anonymous referee and 2 editors of this journal are much appreciated. The first 2 authors are thankful for financial support from Taiwan's Ministry of Science and Technology (MOST 104-2410H-424-015 and MOST104-2410-H-009-052).

\section{References}

1. The State Council of the People's Republic of China, 2015. British economist upbeat about China's economy, from english.gov.cn/news/top_news/2015/04/02/ content_281475081765524.htm

2. HU J.L., WANG S.C. Total-factor energy efficiency of regions in China. Energy Policy 34, 3206, 2006.

3. HONMA S., HU J.L. Total-factor energy efficiency of regions in Japan. Energy Policy 36, 821, 2008.

4. ZHOU P., ANG B.W., POH K.L. A survey of data envelopment analysis in energy and environmental studies. Eur. J. Oper. Res. 189, 1, 2008.

5. ZHOU P., ANG B.W., HAN J.Y. Total factor carbon emission performance: A Malmquist index analysis. Energ. Econ. 32, 194, 2010.

6. LI L.B., HU J.L. Ecological total-factor energy efficiency of regions in China. Energy Policy 46, 216, 2012.

7. MANDAL S.K. Do undesirable output and environmental regulation matter in energy efficiency analysis? Evidence from Indian cement industry. Energy Policy 38, 6076, 2010.

8. YANG H., POLLITT M. The necessity of distinguishing weak and strong disposability among undesirable outputs in DEA: Environmental performance of Chinese coal-fired power plants. Energy Policy 38, 4440, 2010.

9. SUEYOSHI T., GOTO M. DEA approach for unified efficiency measurement: Assessment of Japanese fossil fuel power generation. Energ. Econ. 33, 292, 2011.

10. SUEYOSHI T., GOTO M. DEA radial measurement for environmental assessment and planning: Desirable procedures to evaluate fossil fuel power plants. Energy Policy 41, 422, 2012.

11. SUEYOSHI T., GOTO M. Data envelopment analysis for environmental assessment: Comparison between public and private ownership in petroleum industry. Eur. J. Oper. Res. 216, 668, 2012.

12. FARRELL M.J. The measurement of productive efficiency. J. R. Stat. Soc. Ser. A.-G. 120, 253, 1957.

13. CHARNES A., COOPER W.W., RHODES E. Measuring the efficiency of decision making units. Eur. J. Oper. Res. 2, 429, 1978.

14. BANKER R.D., CHARNES A., COOPER W.W. Some models for estimating technical and scale inefficiencies in data envelopment analysis. Manage. Sci. 30, 1078, 1984.

15. TONE K. A slacks-based measure of efficiency in data envelopment analysis. Eur. J. Oper. Res. 130, 498, 2001.

16. TONE K. Dealing with undesirable outputs in DEA: A slacks-based measure (SBM) approach. GRIPS Research Report Series, 1, 2003.

17. TONE K. A Hybrid measure of efficiency in DEA. GRIPS Research Report Series, 1, 2004.

18. ZHOU P., ANG B.W., POH K.L. Slacks-based efficiency measures for modeling environmental performance. Ecol. Econ. 60, 111, 2006. 
19. ZHOU Y., XING X., FANG K., LIANG D., XU C. Environmental efficiency analysis of power industry in China based on an entropy SBM model. Energy Policy 57, 68, 2013.

20. LU C.C., CHIU Y.H., SHYU M.K., LEE J.H. Measuring $\mathrm{CO}_{2}$ Emission efficiency in OECD countries: Application of the hybrid efficiency model. Econ. Model. 32, 130, 2013.

21. CHANG Y.T., PARK H.S., JEONG J.B., LEE J.W. Evaluating economic and environmental efficiency of global airlines: A SBM-DEA approach. Transport. Res. D.-Tr. E. 27, 46, 2014.

22. TAO X., WANG P., ZHU B. Provincial green economic efficiency of China: A non-separable input-output SBM approach. Appl. Energ. 171, 58, 2016.

23. CAVES D.W., CHRISTENSEN L.R., DIEWERT W.E. The economic theory of index numbers and the measurement of input, output, and productivity. Econometrica 50, 1393, 1982.

24. FÄRE R., GROSSKOPF S., NORRIS M., ZHANG Z. Productivity growth, technical progress, and efficiency change in industrialized countries. Am. Econ. Rev. 84, 66, 1994,

25. RAMANATHAN R. An analysis of energy consumption and carbon dioxide emissions in countries of the Middle East and North Africa. Energy 30, 2831, 2005.

26. KIM K., KIM Y. International comparison of industrial $\mathrm{CO}_{2}$ emission trends and the energy efficiency paradox utilizing production-based decomposition. Energ. Econ. 34, 1724, 2012.

27. WEI Y.M., LIAO H., FAN Y. An empirical analysis of energy efficiency in China's iron and steel sector. Energy 32, 2262, 2007.

28. CHANG M.C. Applying the energy productivity index that considers maximized energy reduction on SADC (Southern Africa Development Community) members. Energy 95, 313, 2016.

29. ZHANG N., ZHOU P., KUNG C.C. Total-factor carbon emission performance of the Chinese transportation industry: A bootstrapped non-radial Malmquist index analysis. Renew. Sust. Energ. Rev. 41, 584, 2015,

30. O'DONNELL C.J., RAO D.P., BATTESE G.E. Metafrontier frameworks for the study of firm-level efficiencies and technology ratios. Empir. Econ. 34, 231, 2008.

31. LI K., LIN B. Metafroniter energy efficiency with $\mathrm{CO}_{2}$ emissions and its convergence analysis for China. Energ. Econ. 48, 230, 2015.

32. YAO X., ZHOU H., ZHANG A., LI A. Regional energy efficiency, carbon emission performance and technology gaps in China: A meta-frontier non-radial directional distance function analysis. Energy Policy 84, 142, 2015.

33. CHANG M.C. Room for improvement in low carbon economies of G7 and BRICS countries based on the analysis of energy efficiency and environmental Kuznets curves. J. Clean. Prod. 99, 140, 2015.

34. WANG Q., SU B., SUN J., ZHOU P., ZHOU D. Measurement and decomposition of energy-saving and emissions reduction performance in Chinese cities. Appl. Energ. 151, 85, 2015.

35. WANG Q., ZHAO Z., ZHOU P., ZHOU D. Energy efficiency and production technology heterogeneity in China: A metafrontier DEA approach. Econ. Model. 35, 283, 2013.

36. GUO X.D., ZHU L., FAN Y., XIE B.C. Evaluation of potential reductions in carbon emissions in Chinese provinces based on environmental DEA. Energy Policy 39, 2352, 2011.

37. CHOI Y., ZHANG N., ZHOU P. Efficiency and abatement costs of energy-related $\mathrm{CO}_{2}$ emissions in China: A slacksbased efficiency measure. Appl. Energ. 98, 198, 2012.

38. WU F., FAN L.W., ZHOU P., ZHOU D.Q. Industrial energy efficiency with $\mathrm{CO}_{2}$ emissions in China: A nonparametric analysis. Energy Policy 49, 164, 2012.

39. YAO X., WATANABE C., LI Y. Institutional structure of sustainable development in BRICS: Focusing on ICT utilization. Technol. Soc. 31, 9, 2009.

40. World Bank, 2014. Indicators. Available in. http://data. worldbank.org/indicator (accessed 16.04.14.).

41. DE CASTRO CAMIOTO F., MORALLES H.F., MARIANO E.B., DO NASCIMENTO REBELATTO D.A. Energy efficiency analysis of G7 and BRICS considering total-factor structure. J. Clean. Prod. 122, 67, 2016.

42. DINDA S. Environmental Kuznets curve hypothesis: A survey. Ecol. Econ. 49, 431, 2004.

43. STERN D.I., COMMON M.S., BARBIER E.B. Economic growth and environmental degradation: The environmental Kuznets curve and sustainable development. World. Dev. 24, 1151, 1996.

44. GROSSMAN G.M., KRUEGER A.B. Environmental impacts of a North American Free Trade Agreement. National Bureau of Economic Research Working Paper 3914, NBER, Cambridge MA. 1991.

45. AKBOSTANCI E., TÜRÜT-AŞIK S., TUNÇ G.İ. The relationship between income and environment in Turkey: Is there an environmental Kuznets curve? Energy Policy 37, $861,2009$.

46. HE J., RICHARD P. Environmental Kuznets curve for $\mathrm{CO}_{2}$ in Canada. Ecol. Econ. 69, 1083, 2010.

47. FODHA M., ZAGHDOUD O. Economic growth and pollutant emissions in Tunisia: An empirical analysis of the environmental Kuznets curve. Energy Policy 38, 1150, 2010.

48. LEVINSON A. The ups and downs of the environmental Kuznets curve. Rec. Adv. Env. Eco. 119, 2002. 